\title{
Effects of NB001 and gabapentin on irritable bowel syndrome-induced behavioral anxiety and spontaneous pain
}

\author{
Ming-Ming Zhang ${ }^{1,2 \dagger}$, Shui-Bing Liu ${ }^{2,3 \dagger}$, Tao Chen ${ }^{1,3}$, Kohei Koga ${ }^{2,3}$, Ting Zhang ${ }^{1}$, Yun-Qing Li ${ }^{*}$ and Min Zhuo ${ }^{2,3^{*}}$
}

\begin{abstract}
Irritable bowel syndrome (IBS) is characterized by recurrent abdominal discomfort, spontaneous pain, colorectal hypersensitivity and bowel dysfunction. Patients with IBS also suffer from emotional anxiety and depression. However, few animal studies have investigated IBS-induced spontaneous pain and behavioral anxiety. In this study, we assessed spontaneous pain and anxiety behaviors in an adult mouse model of IBS induced by zymosan administration. By using Fos protein as a marker, we found that sensory and emotion related brain regions were activated at day 7 after the treatment with zymosan; these regions include the prefrontal cortex, anterior cingulate cortex, insular cortex and amygdala. Behaviorally, zymosan administration triggered spontaneous pain (decreased spontaneous activities in the open field test) and increased anxiety-like behaviors in three different tests (the open field, elevated plus maze and light/dark box tests). Intraperitoneal injection of NB001, an adenylyl cyclase 1 (AC1) inhibitor, reduced spontaneous pain but had no significant effect on behavioral anxiety. In contrast, gabapentin reduced both spontaneous pain and behavioral anxiety. These results indicate that NB001 and gabapentin may inhibit spontaneous pain and anxiety-like behaviors through different mechanisms.
\end{abstract}

Keywords: Irritable bowel syndrome, Zymosan, Visceral pain, Spontaneous pain, Anxiety

\section{Background}

Visceral pain occurs after mechanical or chemical stimulation in and around the internal organs. This form of pain is vague and poorly localized [1-4]. Typical phenotypes of visceral pain include hyperalgesia, in which enhanced pain responses are induced by weak noxious visceral stimuli, and allodynia, in which innocuous visceral stimuli can cause pain. In addition, spontaneous pain or discomfort can frequently be observed [5]. Irritable bowel syndrome (IBS), a major form of chronic visceral pain, is accompanied by visceral hyperalgesia, abnormal bowel habits and spontaneous pain or discomfort [6,7]. Recent studies indicate that an enhanced primary sensory afferent derived from the colorectum maintained IBS-related pain and

\footnotetext{
*Correspondence: deptanat@fmmu.edu.cn; min.zhuo@utoronto.ca ${ }^{\dagger}$ Equal contributors

'Department of Anatomy, Histology, Embryology \& K. K. Leung Brain Research Centre, The Fourth Military Medical University, Xian, Shanxi 710032, China

${ }^{2}$ Department of Physiology, Faculty of Medicine, University of Toronto, 1 King's College Circle, Toronto, Ontario M5S 1A8, Canada Full list of author information is available at the end of the article
}

associated colorectal hypersensitivity [7-9]. It is very likely that enhanced sensory inputs into the central nervous system may trigger long-term changes in brain areas associated with emotional and cognitive processing. Unsurprisingly, it has been reported that IBS is accompanied by severe anxiety, stress and depression [10-15]. Most of previous animal studies of IBS only focused on sensory mechanisms; few examined behavioral and emotional changes in IBS.

Cortical and subcortical areas, such as the prefrontal cortex (PFC), anterior cingulate cortex (ACC), insular cortex and amygdala, are important for processing pain, discomfort and emotional responses [16-23]. Animal and human brain imaging studies show that IBS affects neuronal activities in these brain areas, specifically the ACC [24-30]. In previous studies, we found that pain and pain-related emotional changes triggered long-term potentiation (LTP) of synaptic transmission in the ACC [18,31,32]. Calcium-stimulated adenylyl cyclase subtype 1 (AC1) plays important roles in pain-related LTP in the ACC as well as in injury-induced plastic changes [33-36]. 
Genetic inhibition of $\mathrm{AC} 1$ or administration of the $\mathrm{AC} 1$ inhibitor NB001 causes analgesic effects in mice with somatic tissue injury, inflammation or muscle pain [37-39]. However, the possible effect of an AC1 inhibitor on IBS-induced pain or anxiety has not been investigated.

In the present study, we began by labeling Fos protein, a marker of neural activity, in mouse brains to detect the activation of brain areas that are important for pain processing as well as the processing of anxiety and fear. Second, we wanted to establish behavioral measurement of spontaneous pain, discomfort and behavioral anxiety in adult mice with intra-colonic injection of zymosan, a common animal model to mimic the clinical IBS $[40,41]$. Finally, we evaluated the effects of the AC1 inhibitor NB001 and gabapentin, a commonly used anticonvulsant and analgesic component in treating seizures and somatic neuropathic pain [42-44], on spontaneous pain and behavioral anxiety, as well as other behavioral responses.

\section{Results}

\section{Zymosan increases the expression of Fos protein in the} central nervous system

First, we sought to determine whether IBS activates sensory and emotion related brain areas. Neuronal Fos protein expression is commonly used as a correlative indicator of neuronal activity induced by somatic or visceral noxious stimuli $[20,45,46]$. We performed Fos immunohistochemical staining to determine whether cortical and subcortical neurons are involved in zymosaninduced colitis on day 7 after injections of zymosan. This time point was chosen because our preliminary experiments have indicated that the mice display obvious visceral pain behaviors on day 7 after injections of zymosan. Quantification of Fos-immunoreactive (Fos-ir) neurons showed that Fos was expressed at higher levels in many areas of the forebrain, subcortex and brainstem of zymosan-treated mice on day 7 than in the same brain regions of saline-treated mice on day 7 ( $n=6$ slices from 6 mice per group; Figure 1). In forebrain areas, zymosan treatment induced prominent Fos staining in layer II-III of the ACC (zymosan: 186.4 \pm 8.9 ; saline: 14.9 \pm 2.5 ; unpaired $t$-test, $P<0.001$ ), the medial PFC (zymosan: $268.7 \pm 11.4$; saline: $59.6 \pm 5.3$; unpaired $t$-test, $P<0.001)$ and layer II-III of the insular cortex (zymosan: 225.4 \pm 12.3; saline: $45.2 \pm 2.1$; unpaired $t$-test, $P<0.001)$. In the subcortex areas, Fos expression was mainly found in the central nucleus of the amygdaloid complex (zymosan: $388.5 \pm 10.6$; saline: $33 \pm 3.3$; unpaired $t$-test, $P<0.001)$. In the midbrain, zymosan treatment augmented Fos expression within the ventral posterolateral region of the periaqueductal gray (PAG) (zymosan: $98.3 \pm 5.2$; saline: $9.5 \pm 1.9$; unpaired $t$-test, $P<0.001)$. In the brainstem, abundant Fos expression was also observed in the lateral region of the parabrachial nucleus $(\mathrm{PBN})$ (zymosan: $132.5 \pm 6.6$; saline:
$17.4 \pm 1.1$; unpaired $t$-test, $P<0.001)$ and in the medial and commissural parts of the nucleus of solitary tract (NTS) (zymosan: $87.9 \pm 7.1$; saline: $7.9 \pm 1.0$; unpaired $t$-test, $P<0.001)$. These observations suggest that brain regions associated with pain and emotion are activated in response to intracolonic injection of zymosan.

\section{Zymosan-induced visceral pain behaviors}

We showed that brain regions related to pain and emotional processing were activated in zymosan-induced colitis, as shown by Fos immunohistochemical staining. Next, we measured behavioral responses to confirm that visceral pain was induced by intracolonic injection of zymosan in adult mice $[41,47,48]$. As reported previously, mouse postures defined as visceral pain-related behaviors include licking of the abdomen in the absence of other grooming behavior, whole-body stretching, flattening the abdomen against the floor, or contracting the abdominal wall such that an arched posture is adopted for 1-2 sec (abdominal retractions) [49]. To evaluate the time course of zymosan-induced visceral pain, 12 mice were divided into zymosan- and saline-treated groups ( $n=6$ mice per group). After intracolonic injections of zymosan or saline for three consecutive days (Figure 2A), mice were then tested for visceral pain behaviors on days 1, 7, 14 and 28 (Figure 2B). We found that zymosan-treated mice exhibited obvious visceral pain-related behaviors on the first day compared to saline-treated mice (zymosan: $27.7 \pm 1.6$; vs. saline: $3.2 \pm 1.1 ; P<0.001$; repeated measures ANOVA followed by post hoc comparison with LSD test; Figure 2C). Abdominal, visceral pain-related behaviors persisted for a long period of time (zymosan: day 7: $25.3 \pm 2.1$; day 14: $26.8 \pm 2.1$; day $28: 26.0 \pm 2.2$; vs. saline: day $7: 3.5 \pm 0.9$; day 14: $3.7 \pm 0.9$; day 28: $3.3 \pm 0.7 ; P<0.001$; repeated measures ANOVA followed by post hoc comparison with LSD test; Figure 2B-C). In zymosan-treated mice, there were no differences in the quantity of pain-related behaviors within time points $\left(F_{(3,20)}=0.25, P=0.86\right.$; one way ANOVA; Figure 2C), suggesting that intracolonic injection of zymosan can induce stable, chronic visceral pain. Thus, our data indicate that intracolonic injection of zymosan can induce obvious and persistent visceral pain behaviors in mice.

\section{Spontaneous pain increased in zymosan-treated mice}

To further explore spontaneous pain of zymosan-treated mice, we carried out experiments using the open field test. To avoid habituation effects, independent groups were used for each testing day. Thus, each mouse was tested only once in the open field. In the open field test, both spontaneous activities and travel distance were measured automatically. Spontaneous activities include vertical (rearing), ambulatory (horizontal activity), stereotypic (absence of locomotion but presence of repetitive, 


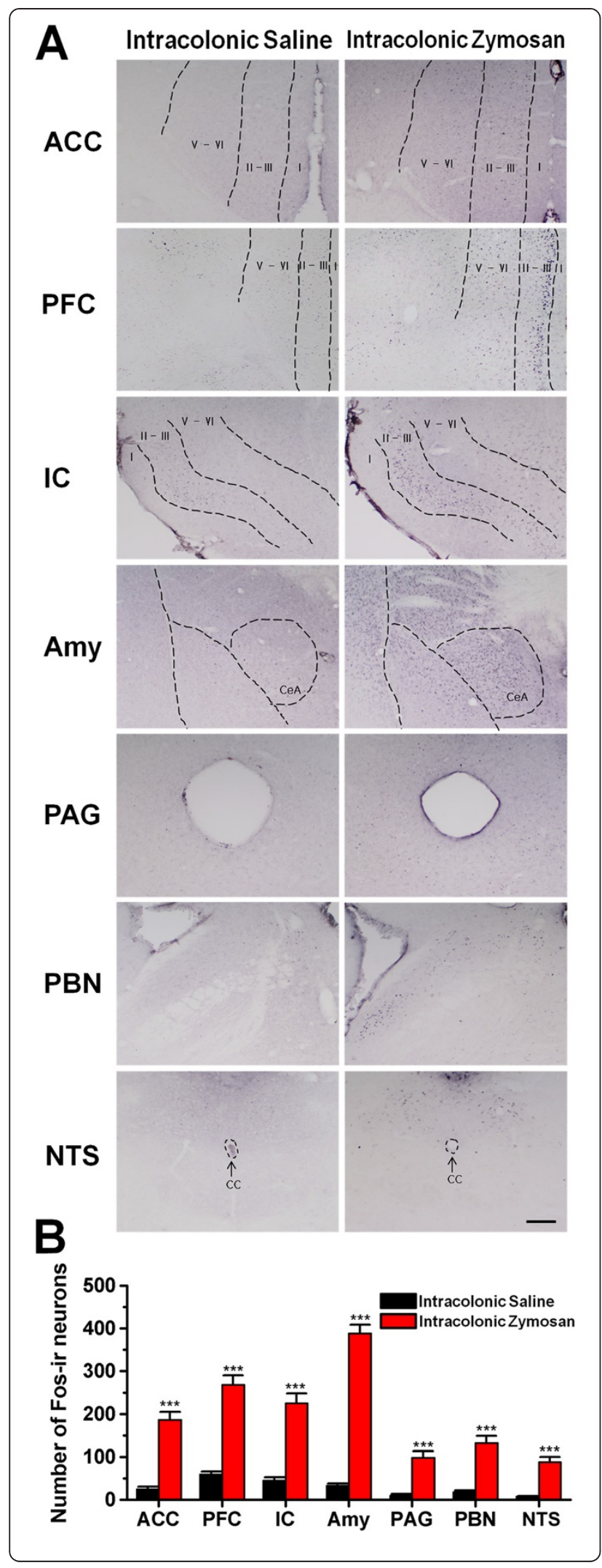

Figure 1 The expression of Fos protein was upregulated in different brain regions in zymosan-treated mice. (A) Immunohistochemical staining for Fos in the ACC (anterior cingulate cortex, $0.98 \mathrm{~mm}$ prior to bregma), PFC (prefrontal cortex, $1.78 \mathrm{~mm}$ prior to bregma), IC (insular cortex, $1.18 \mathrm{~mm}$ prior to bregma), Amy (amygdala, $1.46 \mathrm{~mm}$ posterior to bregma), PAG (periaqueductal gray, $4.72 \mathrm{~mm}$ posterior to bregma), PBN (parabrachial nucleus, $5.20 \mathrm{~mm}$ posterior to bregma) and NTS (nucleus of solitary tract, $7.76 \mathrm{~mm}$ posterior to bregma) at day 7 after intracolonic injection of zymosan or saline (control). (CeA: central amygdala; cc: central canal; Scale

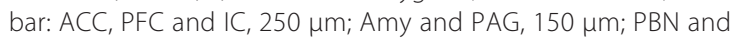
NTS, $100 \mu \mathrm{m})$. (B) Histogram showing the quantification of Fos-immunoreactive (Fos-ir) neurons in the above brain regions of saline- and zymosan-treated mice ( $n=6$ slices per mouse; 6 mice per group). ${ }^{*}$ denotes a significant difference between zymosan- and saline-treated mice.

invariant behaviors such as grooming and head bobbing) and jump (escape latency) behaviors. Interestingly, counts for all four of these behaviors were significantly decreased in zymosan-treated mice on day 1 compared to salinetreated groups. These decreases maintained on days 7,14 and 28 ( $\mathrm{n}=6$ mice per group for each testing day, twoway ANOVA followed by post hoc comparison with LSD test; Table 1, Figure 3A). There were no significant differences among the day 1, 7, 14 and 28 groups (Vertical: $F_{(3,40)}=2.57, P=0.07$; Ambulatory: $F_{(3,40)}=$ 2.41, $P=0.08$; Stereotypic: $F_{(3,40)}=2.21, P=0.10$; Jump: $F_{(3,40)}=0.14, P=0.94$; two-way ANOVA followed by

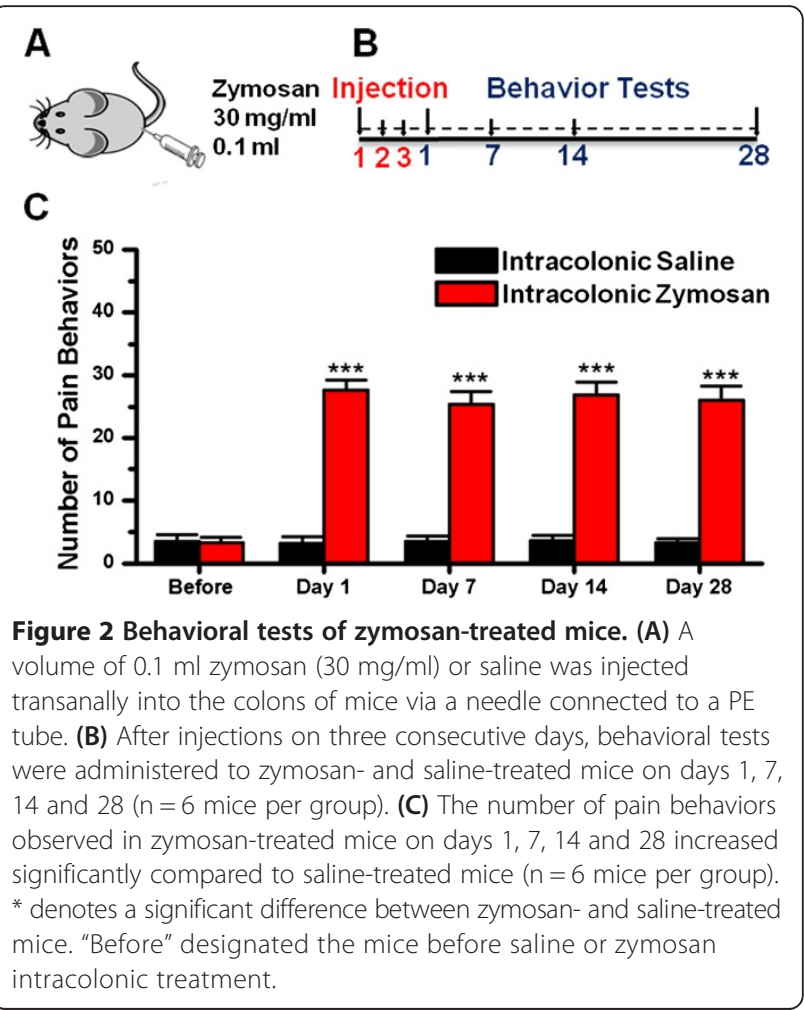


Table 1 Spontaneous activities counts of mice in the open field test

\begin{tabular}{|c|c|c|c|c|}
\hline Counts & Day & Intracolonic saline & Intracolonic zymosan & $P$ \\
\hline \multirow[t]{4}{*}{ Vertical } & 1 & $800.5 \pm 63.8$ & $492.2 \pm 42.4$ & $<0.001$ \\
\hline & 7 & $1055.3 \pm 72.8$ & $498.0 \pm 51.8$ & $<0.001$ \\
\hline & 14 & $976.7 \pm 50.6$ & $450.5 \pm 53.2$ & $<0.001$ \\
\hline & 28 & $1026.8 \pm 58.6$ & $438.2 \pm 49.9$ & $<0.001$ \\
\hline \multirow[t]{4}{*}{ Ambulatory } & 1 & $1979.3 \pm 158.2$ & $1404.0 \pm 133.3$ & $<0.05$ \\
\hline & 7 & $2374.7 \pm 155.7$ & $1343.0 \pm 152.5$ & $<0.001$ \\
\hline & 14 & $2336.7 \pm 172.2$ & $1155.0 \pm 117.4$ & $<0.001$ \\
\hline & 28 & $2448.3 \pm 161.9$ & $1279.7 \pm 147.4$ & $<0.001$ \\
\hline \multirow[t]{4}{*}{ Stereotypic } & 1 & $5011.3 \pm 254.8$ & $4094.3 \pm 257.1$ & $<0.05$ \\
\hline & 7 & $4961.3 \pm 260.0$ & $3024.8 \pm 214.6$ & $<0.001$ \\
\hline & 14 & $5206.7 \pm 265.7$ & $3124.8 \pm 289.2$ & $<0.001$ \\
\hline & 28 & $4862.7 \pm 259.3$ & $2970.2 \pm 218.7$ & $<0.001$ \\
\hline \multirow[t]{4}{*}{ Jump } & 1 & $120.8 \pm 13.9$ & $60.7 \pm 10.6$ & $<0.01$ \\
\hline & 7 & $129.5 \pm 10.9$ & $62.7 \pm 9.7$ & $<0.001$ \\
\hline & 14 & $122.5 \pm 14.0$ & $67.0 \pm 8.5$ & $<0.01$ \\
\hline & 28 & $117.8 \pm 12.3$ & $64.7 \pm 11.5$ & $<0.01$ \\
\hline
\end{tabular}

$P:$ in comparison with saline intracolonic treated group; $\mathrm{n}=6$ mice per group.

post hoc comparison with LSD test; Table 1, Figure 3A). As comparison, there were no significant differences among saline-treated mice $(n=6$ mice for each time point) and naïve mice ( $\mathrm{n}=6$ mice). An analysis of our behavioral data with 5 -min epochs showed that the counts decreased consistently in zymosan-treated mice within the 30-min testing time period compared to saline-treated mice (Figure 3B).

In addition to four major behavioral counts, the total travel distance of zymosan-treated mice in the open field also markedly decreased days $1\left(F_{(1,40)}=4.83, P<0.05\right)$, $7\left(F_{(1,40)}=10.56, P<0.01\right), 14\left(F_{(1,40)}=15.75, P<0.001\right)$ and $28\left(F_{(1,40)}=17.97, P<0.001\right)(\mathrm{n}=6$ mice per group for each testing day, two-way ANOVA followed by post hoc comparison with LSD test; Figure 3D). The magnitude of reduction was similar among the day 1, 7, 14 and 28 groups $\left(F_{(3,40)}=0.83, P=0.49\right.$; two-way ANOVA; Figure $3 \mathrm{D})$. These results consistently suggest that behavioral changes in the open field test can be used to predict the magnitude of spontaneous pain.

\section{Zymosan-induced anxiety-like behaviors}

Anxiety-like behavior in the open field is often assessed by measuring exploratory behavior in the central field within the first few minutes of beginning the open field test $[37,50]$. Therefore, we analyzed the travel distance within the central zone for zymosan-treated groups at different time points, using a 5-min epoch. We found that zymosan-treated mice travelled less distance within the central area within the first 5 min of starting the test compared to saline-treated mice (zymosan: day 1: $3.0 \pm 0.9 \mathrm{~m}$,
$P<0.05$; day 7: $2.5 \pm 0.9 \mathrm{~m}, P<0.05$; day $14: 3.2 \pm 0.8 \mathrm{~m}$, $P<0.05$; day 28: $3.1 \pm 0.8 \mathrm{~m}, P<0.05$; vs. saline: $6.9 \pm$ $1.1 \mathrm{~m} ; \mathrm{n}=6$ mice per group for each testing day, two-way ANOVA followed by post hoc comparison with Dunnett's test; Figure 3E). The magnitude of reduction was similar among the day $1,7,14$ and 28 groups $\left(F_{(3,20)}=0.06\right.$, $P=0.98$; two-way ANOVA; Figure $3 \mathrm{E})$. We also found that zymosan-treated mice spent less time in the central area within the first $5 \mathrm{~min}$ of starting the test compared to saline-treated mice (zymosan: day 1: $3.2 \pm 0.6 \mathrm{~s}, P<0.001$; day 7: $2.7 \pm 0.5 \mathrm{~s}, P<0.001$; day $14: 3.5 \pm 0.5 \mathrm{~s}, P<0.001$; day 28: $3.1 \pm 0.6 \mathrm{~s}, P<0.001$; vs. saline: $8.9 \pm 0.9 \mathrm{~s} ; \mathrm{n}=6$ mice per group for each testing day, two-way ANOVA followed by post hoc comparison with Dunnett's test). These findings indicate that zymosan-treated mice likely experience more anxiety than saline-treated mice.

To further evaluate changes in anxiety-related behaviors, we used the elevated plus maze and a light/dark box tests. The elevated plus maze is based on an anxiogenic agent, such as an unprotected elevated area, the anxiety level being expressed by the number of entries into and the length of time spent in the aversive area [51]. The light/ dark box is based on the innate aversion of rodents to brightly illuminated areas and on the spontaneous exploratory behavior of rodents in response to stress or anxiety [52]. Firstly, we found that the time spent in the open arms of the elevated plus maze was significantly reduced in mice in the day 1 group compared to saline-treated mice $\left(F_{(1,40)}=22.63, P<0.001 ; \mathrm{n}=6\right.$ mice per group for each testing day, two-way ANOVA followed by post hoc comparison with LSD test; Figure 4A), suggesting that zymosan 

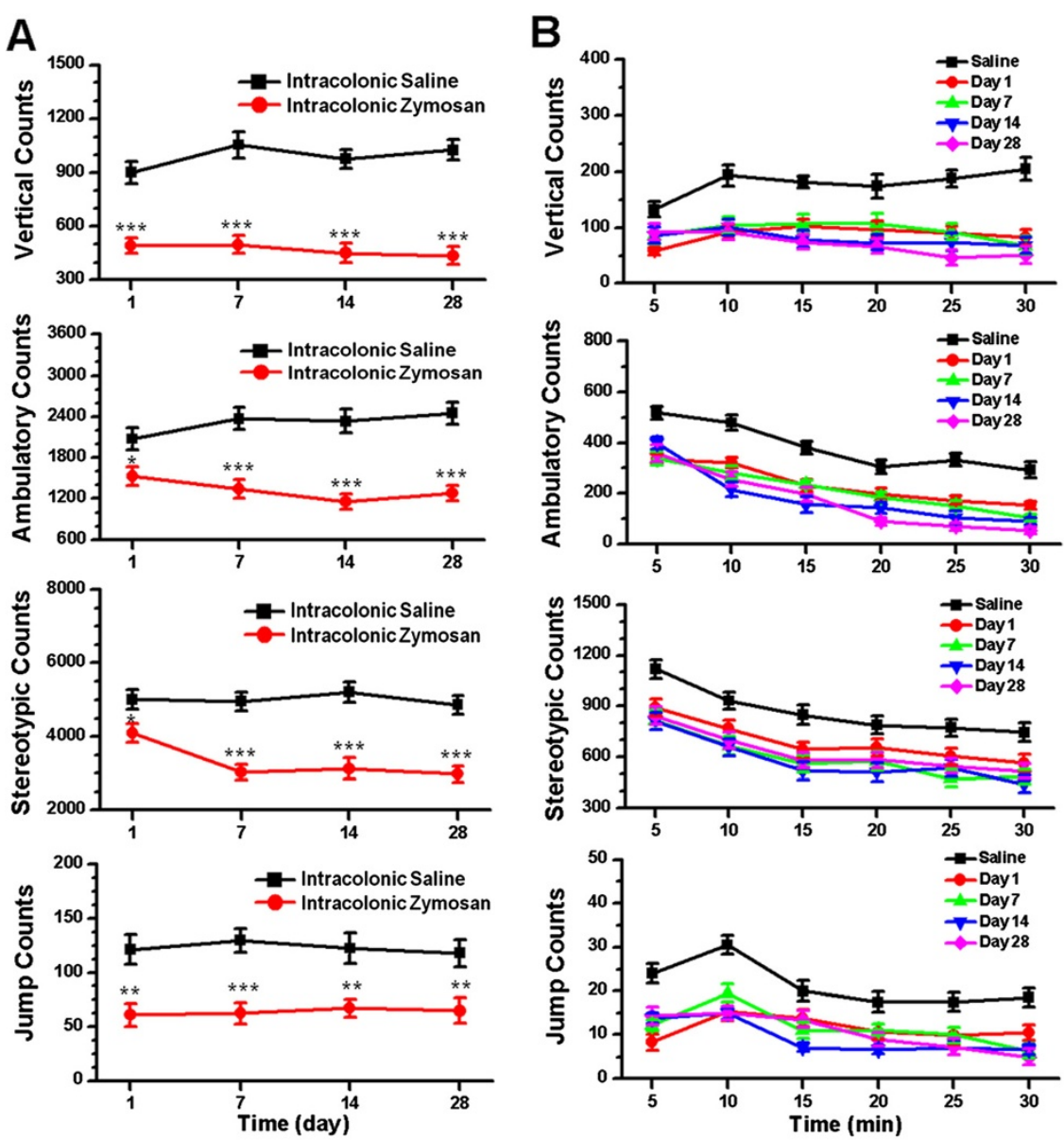

C

Day 1

Day 7

Day 14

Day 28

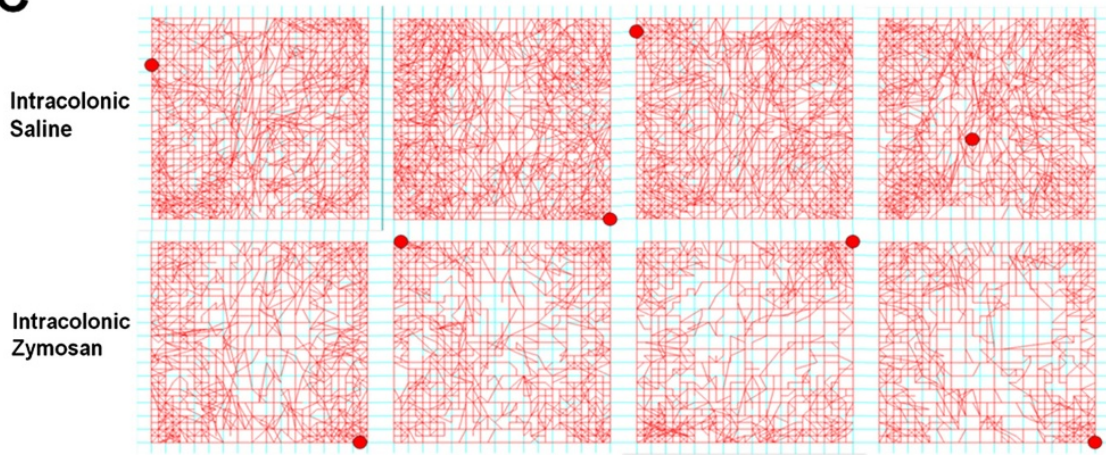

D

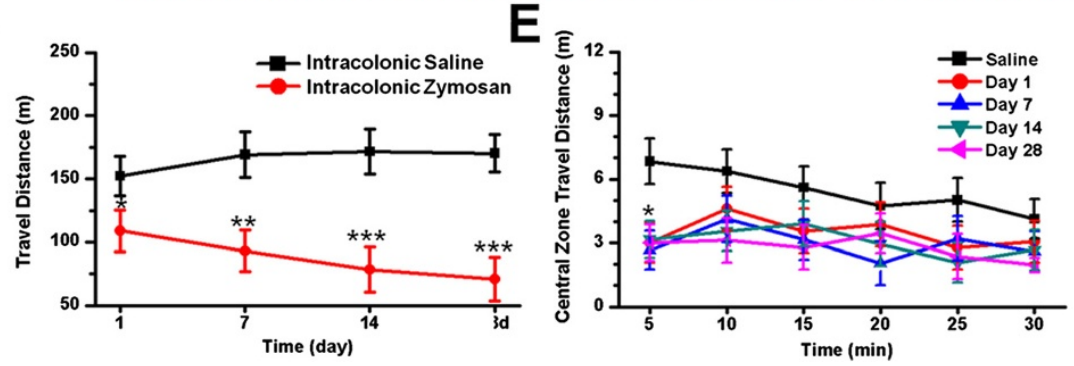

Figure 3 (See legend on next page.) 
(See figure on previous page.)

Figure 3 Behavioral assessment of zymosan-treated mice in the open field. (A) Counts of vertical, ambulatory, stereotypic and jump behaviors in zymosan-treated mice were decreased compared to saline-injected mice on days $1,7,14$ and 28 day ( $n=6$ mice per group for each testing day). * denotes a significant difference between zymosan- and saline-treated mice. (B) Vertical, ambulatory, stereotypic and jump counts over 30 min on days $1,7,14$ and 28 for zymosan-treated mice ( $n=6$ for each testing day) and saline-treated mice ( $n=24$ mice). (C) Representative traces show the movement of zymosan- and saline-treated mice in the open field test over a period of $30 \mathrm{~min}$. (D) Zymosan-treated mice traveled significantly less distance than did saline-treated mice on days 1, 7, 14 and 28 ( $n=6$ mice per group for each testing day). ${ }^{*}$ denotes a significant difference between zymosan- and saline-treated mice. (E) The distance traveled by zymosan-treated mice in the central zone within the first 5 min of the 30-min session of the open field test was significantly reduced on days 1, 7, 14 and 28 ( $n=6$ mice for each testing day) compared to saline-treated mice ( $n=24$ mice). * denotes a significant difference from saline-treated mice.

treatment can induce anxiety in mice. To determine if the anxiety is long-lasting, we measured responses at other time points. We found that zymosan-treated mice spent less time in the open arms of the elevated plus maze on days $7\left(F_{(1,40)}=47.09, P<0.001\right), 14\left(F_{(1,40)}=\right.$ $35.12, P<0.001)$ and $28\left(F_{(1,40)}=35.12, P<0.001\right)(\mathrm{n}=6$ mice per group for each testing day, two-way ANOVA followed by post hoc comparison with LSD test; Figure 4A). There was no difference among the day $1,7,14$ and 28 groups $\left(F_{(3,40)}=0.74, P=0.53\right.$; two-way ANOVA; Figure $4 \mathrm{~A})$. The data suggest that zymosan-treated mice exhibit long-term anxiety that lasted at least 4 weeks. By contrast, there was no difference in the number of total crossings between zymosan-treated mice and salinetreated mice $\left(F_{(1,40)}=1.36, P=0.25\right.$; two-way ANOVA; Figure 4B), indicating that the decreased activity of the zymosan-treated mice in the open arms is not due to hypoactivity.
Finally, we examined behavioral responses in the light/ dark box test. We found that the time spent in the light box was markedly decreased in mice in the day 1 group compared to saline-treated mice $\left(F_{(1,40)}=6.03, P<0.05\right.$; $\mathrm{n}=6$ mice per group for each testing day, two-way ANOVA followed by post hoc comparison with LSD test; Figure 4C). We also examined mice at different time points using the light/dark box to evaluate the time course of zymosan-induced anxiety-like behaviors. Zymosan-treated mice spent less time in the light box on days $7\left(F_{(1,40)}=\right.$ 15.83, $P<0.001), 14\left(F_{(1,40)}=12.44, P<0.01\right)$ and 28 $\left(F_{(1,40)}=9.81, P<0.01\right)(\mathrm{n}=6$ mice per group for each testing day, two-way ANOVA followed by post hoc comparison with LSD test; Figure 4C). There were no significant differences among the day $1,7,14$ and 28 groups $\left(F_{(3,40)}=0.42, P=0.74\right.$; two-way ANOVA; Figure $\left.4 \mathrm{C}\right)$. As in the elevated plus maze, zymosan-treated mice also exhibited anxiety-like behaviors in the light/dark box, and these
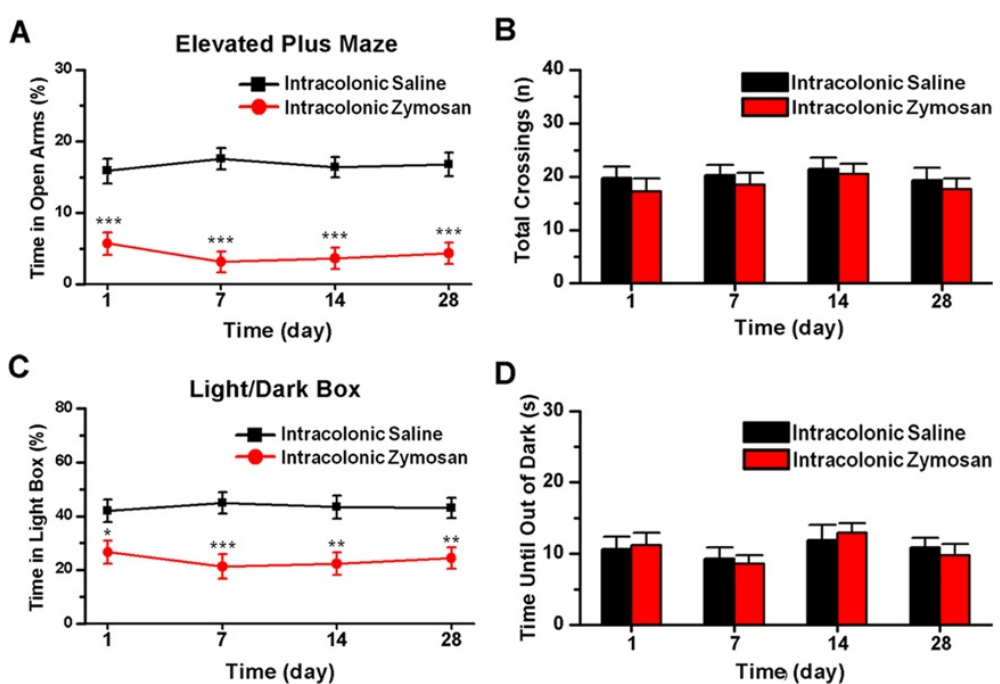

Figure 4 Behavioral assessment of anxiety in zymosan-treated mice. (A) Zymosan-treated mice exhibited significant increases in anxiety-like behaviors in the elevated plus maze compared to saline-treated mice on days $1,7,14$ and 28 ( $n=6$ mice per group for each testing day). ${ }^{*}$ denotes a significant difference between zymosan- and saline-treated mice. (B) No statistically significant difference was observed in the numbers of total crossings (open + closed) of the elevated plus maze between zymosan- and saline-treated mice on testing days $(P=0.25)$. (C) Zymosan-treated mice exhibited significant increases in anxiety-like behaviors in the light/dark box compared to saline-treated mice on days 1,7, 14 and 28 ( $n=6$ mice per group for each testing day). * denotes a significant difference between zymosan- and saline-treated mice. (D) No statistically significant difference between zymosan- and saline-treated mice was observed in the time until mice exited the dark box for the first time in the light/dark box test $(P=0.89)$. 
behaviors lasted at least 4 weeks. There were no significant differences in the time at which animals left the dark box among these groups $\left(F_{(1,40)}=0.02, P=0.89\right.$; two-way ANOVA; Figure 4D), indicating that intracolonic injection of zymosan does not influence the conflict between rodents' exploratory tendencies and aversive properties of the environment.

\section{NB001 and gabapentin alleviated zymosan-induced visceral pain}

Our previous studies indicated that AC1 contributes to chronic pain-related neuronal plasticity in the brain and the spinal cord $[18,19,33,34,53,54]$. Pharmacological inhibition of AC1 by NB001 has analgesic effects in animal models of neuropathic pain and inflammatory pain [37]. However, the effect of NB001 on IBS has not been investigated. Gabapentin is a commonly used anticonvulsant that also has analgesic effects on visceral hyperalgesia $[42-44,55,56]$. Therefore, we decided to investigate the effects of NB001 and gabapentin on visceral pain in zymosan-treated mice. To avoid continuous effects and interaction of drugs, independent groups were used for all testing days. NB001 (3 mg/kg) or gabapentin $(30 \mathrm{mg} / \mathrm{kg})$ was intraperitoneally (IP) injected into zymosan-treated mice 45 min prior to behavioral testing.

We found that NB001 reduced visceral pain behaviors in animals at 1 day after zymosan treatment (NB001: $21.0 \pm 1.8$, saline: $27.0 \pm 2.0, P<0.05 ; \mathrm{n}=6$ mice per group for each testing day, two-way ANOVA followed by post hoc comparison with Dunnett's test; Figure 5). The inhibitory effects of NB001 were also observed at other time points (day 7, NB001: $19.7 \pm 2.4$, saline: $26.7 \pm 1.8$,

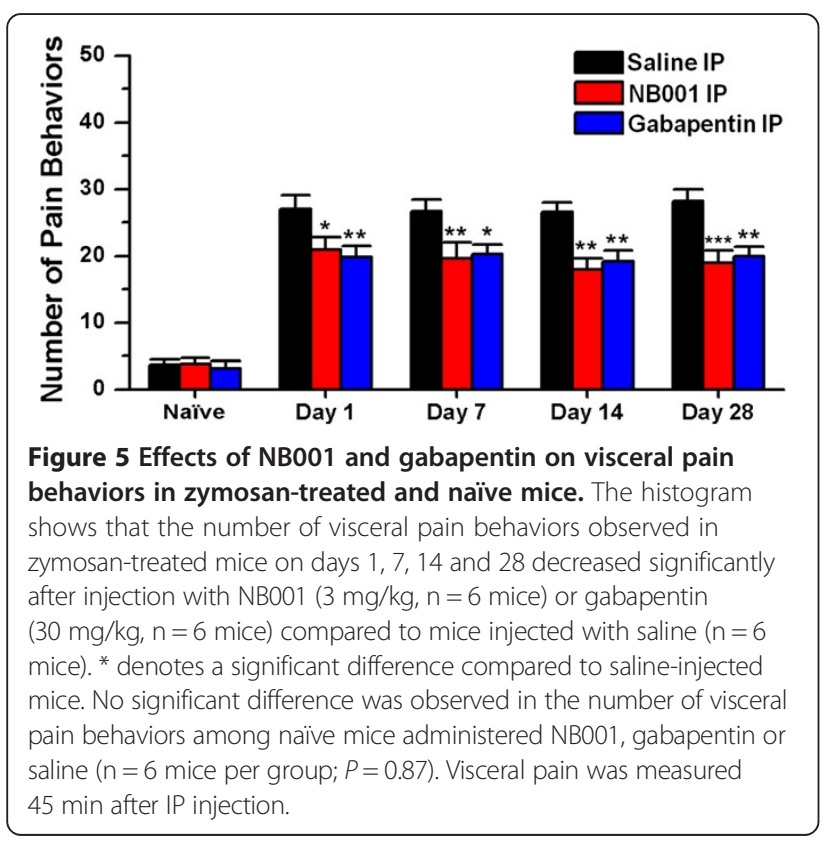

$P<0.01$; day 14 , NB001: $18.0 \pm 1.6$, saline: $26.5 \pm 1.4$, $P<0.01$; day 28, NB001: $19.0 \pm 1.8$, saline: $28.2 \pm 1.8$, $P<0.001 ; \mathrm{n}=6$ mice per group for each testing day, two-way ANOVA followed by post hoc comparison with Dunnett's test; Figure 5). There were no significant differences among the effects of NB001 within each testing days on zymosan-induced visceral pain $\left(F_{(3,20)}=0.43, P=0.73\right.$; one-way ANOVA; Figure 5). We also estimated the maximum possible inhibition (MPI) of NB001 (see Methods). The mean MPI of NB001 on visceral pain behaviors was about $30.5 \%$.

We next examined the effects of gabapentin on visceral pain in zymosan-treated mice. We found that gabapentin injection also produced reduction in visceral pain behaviors (day 1: $19.8 \pm 1.7, P<0.01$; day $7: 20.3 \pm 1.4, P<0.05$; day 14: $19.2 \pm 1.7, P<0.01$; day $28: 20.0 \pm 1.4, P<0.01$; in comparison with saline injection group, $n=6$ mice per group for each testing day, two-way ANOVA followed by post hoc comparison with Dunnett's test; Figure 5). There were no significant differences among the effects of gabapentin within each testing days on zymosan-induced visceral pain $\left(F_{(3,20)}=0.09, P=0.96\right.$; one-way ANOVA; Figure 5). The mean MPI of gabapentin on visceral pain behaviors was $28.6 \%$.

\section{NB001 and gabapentin alleviated zymosan-induced spontaneous pain}

To evaluate further the effects of NB001 and gabapentin, the open field test was used to measure spontaneous pain. NB001 injection into zymosan-treated mice $45 \mathrm{~min}$ prior to open field test increased spontaneous activities on days $1,7,14$ and 28 ( $\mathrm{n}=6$ mice per group for each testing day, two-way ANOVA followed by post hoc comparison with Dunnett's test; Table 2, Figure 6A). Interestingly, NB001 produced more than 50\% MPI on animal's ambulatory counts, particularly on days 1 and 14 (day 1: 103.7\%; day 7: $81.6 \%$; day 14: $94.7 \%$; day 28: $79.9 \%$ ). By contrast, the mean MPIs of NB001 on the other spontaneous activities counts were less than 40\% (vertical: $30.3 \%$; stereotypic: $39.2 \%$; jump: $34.5 \%)$. Thus, the ambulatory counts may be the most sensitive parameter to predict the analgesic effects of drugs on spontaneous visceral pain.

Injection of gabapentin in zymosan-treated mice also increased spontaneous activities on days 1, 7, 14 and 28 in comparison with saline injection group $(n=6$ mice per group for each testing day, two-way ANOVA followed by post hoc comparison with Dunnett's test; Table 2, Figure 6A). Similar to NB001, gabapentin produced more than $50 \%$ MPI on animal's ambulatory counts, especially on day 1 and 14 (day 1: 93.5\%; day 7: 69.3\%; day 14: $90.4 \%$; day 28: $86.4 \%$ ). The mean MPIs of gabapentin on the other spontaneous activities counts were less than 40\% (vertical: $31.3 \%$; stereotypic: $36.9 \%$; jump: $36.8 \%)$. The inhibitory effects produced by NB001 and 
Table 2 Effects of NB001 or gabapentin IP injection on spontaneous activities counts of zymosan-treated mice

\begin{tabular}{|c|c|c|c|c|c|c|}
\hline Counts & Day & Saline IP & NB001 IP & $P$ & Gabapentin IP & $P$ \\
\hline \multirow[t]{4}{*}{ Vertical } & 1 & $437.7 \pm 44.4$ & $612.3 \pm 46.7$ & $<0.05$ & $599.3 \pm 50.4$ & $<0.05$ \\
\hline & 7 & $437.3 \pm 46.1$ & $639.5 \pm 44.8$ & $<0.01$ & $646.2 \pm 45.7$ & $<0.01$ \\
\hline & 14 & $411.2 \pm 46.6$ & $600.2 \pm 46.4$ & $<0.01$ & $623.5 \pm 51.8$ & $<0.01$ \\
\hline & 28 & $400.3 \pm 46.7$ & $605.0 \pm 43.9$ & $<0.01$ & $621.0 \pm 44.9$ & $<0.01$ \\
\hline \multirow[t]{4}{*}{ Ambulatory } & 1 & $1342.5 \pm 197.6$ & $2000.8 \pm 199.2$ & $<0.05$ & $1942.0 \pm 193.9$ & $<0.05$ \\
\hline & 7 & $1345.5 \pm 224.19$ & $2184.5 \pm 214.7$ & $<0.01$ & $2058.3 \pm 205.0$ & $<0.05$ \\
\hline & 14 & $1155.2 \pm 211$ & $2274.2 \pm 208.5$ & $<0.001$ & $2222.8 \pm 212.1$ & $<0.001$ \\
\hline & 28 & $985.3 \pm 172.9$ & $2210.8 \pm 206.1$ & $<0.001$ & $2289.8 \pm 205.0$ & $<0.001$ \\
\hline \multirow[t]{4}{*}{ Stereotypic } & 1 & $3323.5 \pm 252.9$ & $4214.0 \pm 254.7$ & $<0.05$ & $4418.0 \pm 272.7$ & $<0.01$ \\
\hline & 7 & $3039.7 \pm 205.2$ & $4038.2 \pm 271.3$ & $<0.05$ & $3944.3 \pm 306.2$ & $<0.05$ \\
\hline & 14 & $3103.7 \pm 264.8$ & $4002.7 \pm 280.8$ & $<0.05$ & $3885.7 \pm 280.8$ & $<0.05$ \\
\hline & 28 & $2895.2 \pm 296.9$ & $3904.0 \pm 253.4$ & $<0.05$ & $3920.2 \pm 258.4$ & $<0.01$ \\
\hline \multirow[t]{4}{*}{ Jump } & 1 & $55.7 \pm 5.3$ & $79.0 \pm 5.7$ & $<0.01$ & $84.2 \pm 7.2$ & $<0.01$ \\
\hline & 7 & $60.3 \pm 4.9$ & $84.8 \pm 4.7$ & $<0.01$ & $82.0 \pm 6.9$ & $<0.01$ \\
\hline & 14 & $60.5 \pm 5.61$ & $82.2 \pm 5.8$ & $<0.01$ & $88.8 \pm 5.2$ & $<0.01$ \\
\hline & 28 & $63.8 \pm 5.7$ & $89.7 \pm 5.4$ & $<0.01$ & $85.8 \pm 5.6$ & $<0.01$ \\
\hline
\end{tabular}

$P$ : in comparison with saline IP injection group; $\mathrm{n}=6$ mice per group.

gabapentin are similar at the dosage tested (Vertical: $P=0.80$; Ambulatory: $P=0.79$; Stereotypic: $P=0.99$; Jump: $P=0.75$; two-way ANOVA followed by post hoc comparison with LSD test; Table 2, Figure 6A).

In comparison with saline group, the decreased total travel distance in zymosan-treated mice was also relieved by either NB001 (day $1, P<0.05$; day $7, P<0.05$; day 14 , $P<0.01$; day $28, P<0.01 ; \mathrm{n}=6$ mice per group for each testing day, two-way ANOVA followed by post hoc comparison with Dunnett's test; Figure 6B) or gabapentin (day $1, P<0.05$; day $7, P<0.05$; day $14, P<0.01$; day 28 , $P<0.05 ; \mathrm{n}=6$ mice per group for each testing day, twoway ANOVA followed by post hoc comparison with Dunnett's test; Figure 6B). Both drugs produced more than 50\% MPI on total travel distance in zymosan-treated mice, particularly on day 1 (day 1, NB001: 78.8\%, gabapentin: $83.5 \%$; day 7, NB001: $60.4 \%$, gabapentin: $51.6 \%$; day 14, NB001: 59.5\%, gabapentin: 56.3\%; day 28, NB001: 59.2\%, gabapentin: $61.7 \%$ ).

\section{Gabapentin but not NB001 reduced anxiety-like behaviors} in zymosan-treated mice

In the open field, injection of gabapentin (day $1, P<0.01$; day $7, P<0.01$; day $14, P<0.01$; day $28, P<0.01$; in comparison with saline injection group, $n=6$ mice per group for each testing day, two-way ANOVA followed by post hoc comparison with Dunnett's test; Figure 6C), but not NB001(day $1, P=0.52$; day $7, P=0.42$; day $14, P=0.87$; day $28, P=0.75$; in comparison with saline injection group, $\mathrm{n}=6$ mice per group for each testing day, two-way ANOVA followed by post hoc comparison with Dunnett's test; Figure 6C), increased the travel distance within the central zone during the first 5 min of testing on all testing days. We also found that injection of gabapentin (day $1, P<0.01$; day $7, P<0.001$; day $14, P<0.001$; day 28 , $P<0.001$; in comparison with saline injection group, $\mathrm{n}=6$ mice per group for each testing day, two-way ANOVA followed by post hoc comparison with Dunnett's test), but not NB001 (day $1, P=0.37$; day $7, P=0.53$; day $14, P=$ 0.61 ; day $28, P=0.48$; in comparison with saline injection group, $\mathrm{n}=6$ mice per group for each testing day, two-way ANOVA followed by post hoc comparison with Dunnett's test), increased the time spent in the central zone during the first $5 \mathrm{~min}$ of testing on all testing days. Representative traces showed that only gabapentin-injected mice were more willing to explore the central zone (Figure 6D). The mean MPI of gabapentin on the central zone travelling was $96.6 \%$, on the time spent in the central zone was $87.4 \%$.

Mice injected with gabapentin spent more time in the open arms of the elevated plus maze (day $1, P<0.05$; day $7, P<0.001$; day $14, P<0.001$; day $28, P<0.001$; in comparison with saline injection group, $\mathrm{n}=6$ mice per group for each testing day, two-way ANOVA followed by post hoc comparison with Dunnett's test; Figure 7A). The anti-anxiety effects of gabapentin in the elevated plus maze were similar within each testing days $\left(F_{(3,20)}=1.23\right.$, $P=0.33$; one-way ANOVA; Figure 7A). The averaged MPI of gabapentin on zymosan-treated mice in the elevated plus maze was $28.4 \%$. However, NB001 had no obvious effect on it (day $1, P=0.73$; day $7, P=0.73$; day $14, P=0.99$; day $28, P=0.61$; in comparison with saline injection 


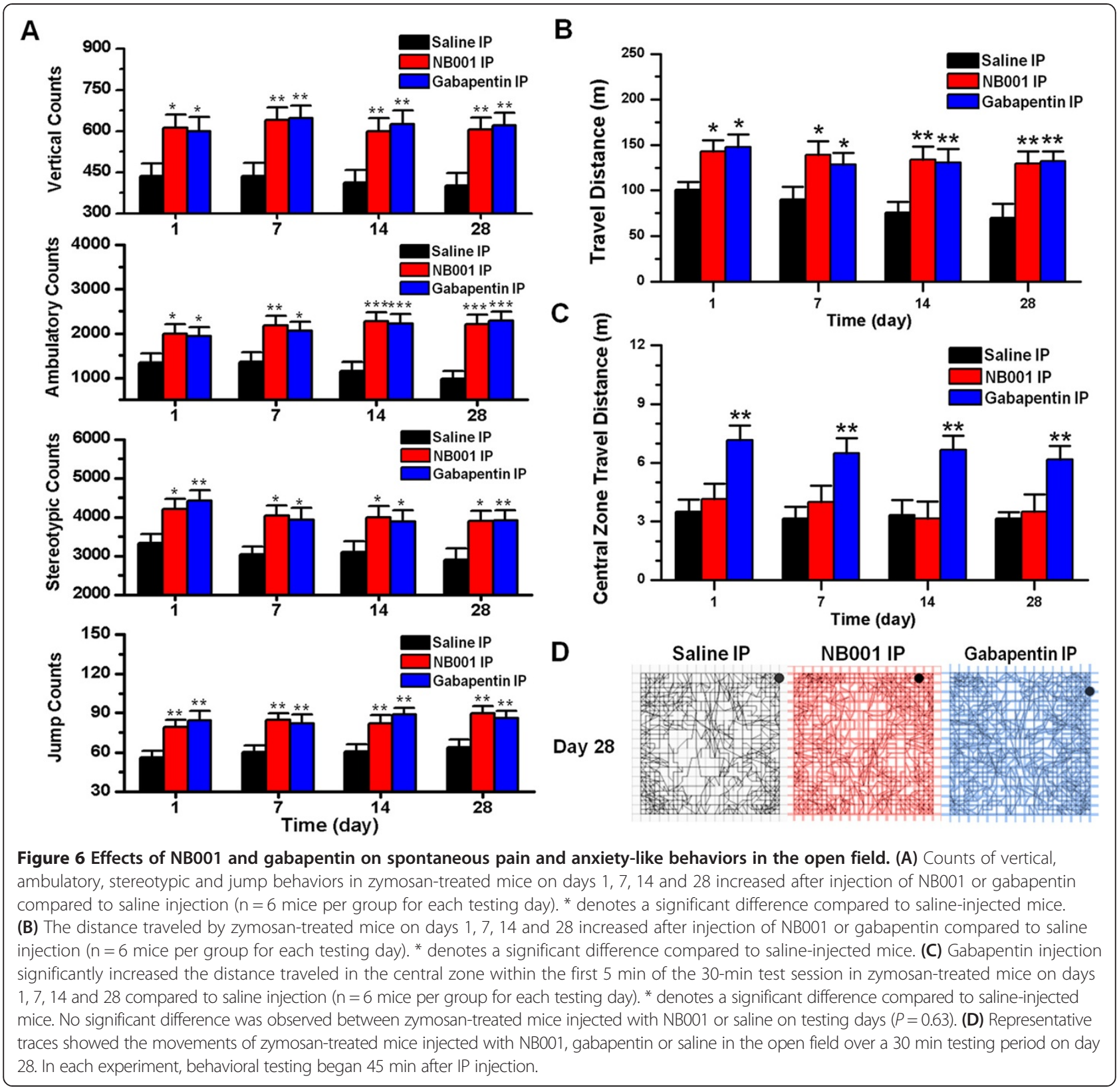

group, $\mathrm{n}=6$ mice per group for each testing day, two-way ANOVA followed by post hoc comparison with Dunnett's test; Figure 7A). Neither drug influenced the total number of crossings in the elevated plus maze at each time point $\left(F_{(3,60)}=0.34, P=0.80\right.$; two-way ANOVA; Figure $\left.7 \mathrm{~B}\right)$.

Finally, to further confirm the effect of gabapentin, we performed experiments using the light/dark box. Mice treated with gabapentin (day $1, P<0.05$; day $7, P<0.05$; day $14, P<0.01$; day $28, P<0.05$; in comparison with saline injection group, $\mathrm{n}=6$ mice per group for each testing day, two-way ANOVA followed by post hoc comparison with Dunnett's test; Figure 7C), but not NB001 (day 1, $P=0.63$; day $7, P=0.85$; day $14, P=0.57$; day $28, P=0.89$; in comparison with saline injection group, $\mathrm{n}=6$ mice per group for each testing day, two-way ANOVA followed by post hoc comparison with Dunnett's test; Figure 7C), spent more time in the light box. Neither drug influenced the time at which animals left the dark box at each time point $\left(F_{(3,60)}=0.71, P=0.55\right.$; two-way ANOVA; Figure 7D), indicating that neither NB001 nor gabapentin influences the conflict between rodents' exploratory tendencies and aversive properties of the environment. Gabapentin produced more than $40 \%$ MPI on zymosan-treated mice in the light/dark box, particularly on day 14 (day 1: $49.4 \%$; day 7: 45.4\%; day 14: $59.2 \%$; day $28: 40.5 \%)$. The data reveal that gabapentin alleviates anxiety-like behaviors via a 

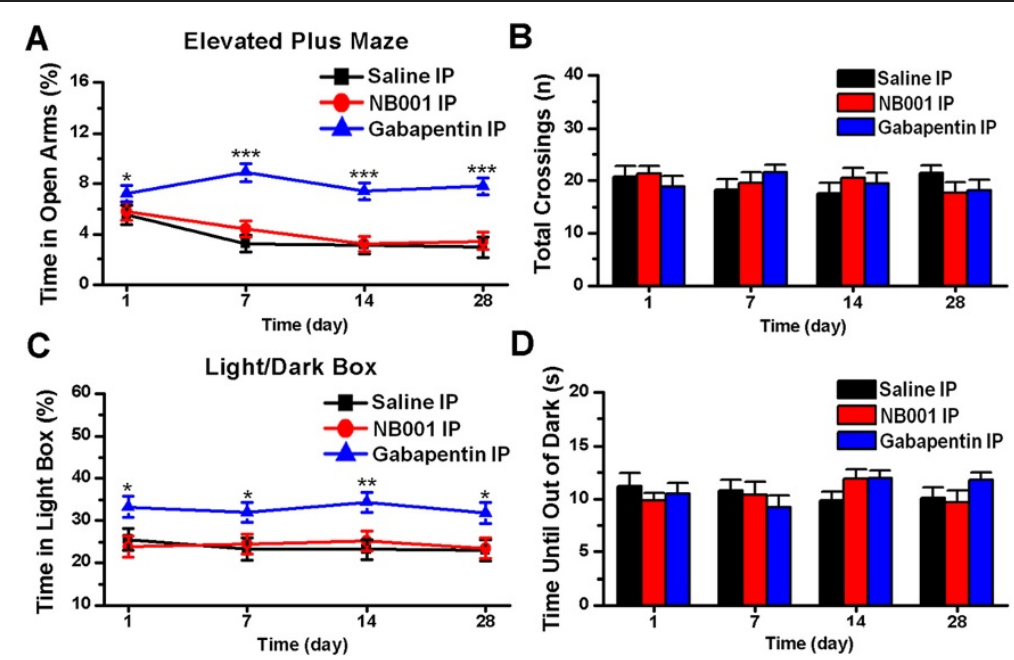

Figure 7 Effects of NB001 and gabapentin on zymosan-induced anxiety-like behaviors. (A) In the elevated plus maze, zymosan-treated mice administered gabapentin exhibited a significant reduction in anxiety-like behaviors on days 1, 7, 14 and 28 compared to mice administered saline ( $n=6$ mice per group for each testing day). * denotes a significant difference compared to saline-injected mice). No statistically significant difference was observed between zymosan-treated mice administered NB001 or saline on testing days $(P=0.43)$. (B) No statistically significant difference was observed in the total number of crossings (open + closed) in the elevated plus maze among zymosan-treated mice administered saline, gabapentin or NB001 on testing days $(P=0.80)$. (C) In the light/dark box test, zymosan-treated mice administered gabapentin exhibited a significant reduction in anxiety-like behaviors on days $1,7,14$ and 28 compared to saline-injected mice $(n=6$ mice per group for each testing day). ${ }^{*}$ denotes a significant difference compared to saline-injected mice). There was no significant difference between zymosan-treated mice administered NB001 ( $n=6$ mice) or saline on testing days $(P=0.97)$. (D) No statistically significant difference was observed in the time until animals leave the dark box in the light/dark box test among zymosan-treated mice administered either saline, gabapentin or NB001 on testing days $(P=0.55)$. In each experiment, behaviors were measured 45 min after IP injection.

mechanism unrelated to antinociception, whereas NB001 is unable to alleviate zymosan-induced anxiety-like behaviors in mice.

\section{Discussion}

In the present study, we examined the neurobehavioral manifestations of zymosan-induced colitis in mice and the effects of NB001 and gabapentin on mice treated with zymosan. Our results included three novel findings: (1) Elevated expression of Fos protein in the brains of zymosan-treated mice demonstrated that cortical areas are involved in the regulation of pain and emotions in mice experiencing zymosan-induced colitis. (2) Zymosantreated mice exhibited obvious, spontaneous visceral pain and anxiety-like behaviors, which persisted for at least 4 weeks after treatment. (3) An investigation of the effects of NB001 and gabapentin on zymosan-induced colitis showed that both drugs had markedly antinociceptive effects. Furthermore, gabapentin, but not NB001, was able to alleviate anxiety in zymosan-treated mice.

Fos protein was expressed at high levels in the brain after the induction of colitis with zymosan

Analysis of serial coronal sections showed elevated levels of Fos protein in the PFC, ACC, insular cortex, amygdala, PAG, PBN and nucleus of solitary tract in zymosantreated mice. Among these brain regions, the PFC, ACC, insular cortex, amygdala and PAG are involved in the processing of pain information and emotional responses [18], the lateral region of $\mathrm{PBN}$ is involved in the processing of general visceral inputs [57], and the medial and commissural parts of the nucleus of solitary tract are the primary targets for afferent vagal fibers [58]. Our observations demonstrate that zymosan-induced colitis causes obvious nociception in mice. The elevated levels of Fos protein in some brain areas related to emotional processing suggests that mice may suffer from emotional disorders following the induction of colitis with zymosan.

\section{Intracolonic injection of zymosan induced chronic visceral pain}

Previous work showed that intracolonic treatment with zymosan could produce a model of chronic colon hypersensitivity involving a transient low-level inflammation $[40,41,47]$. Thus, zymosan is capable of producing visceral hypersensitivity in rodents. Zymosan induced visceral pain is a suitable model to study potential mechanisms underlying visceral hypersensitivity, including human IBS, because of its lack of associated colon pathology. In the present study, typical chronic visceral pain behaviors, such as licking of the abdomen in the absence of other grooming behavior, whole-body stretching, flattening the abdomen against the floor and contracting the abdominal wall, were observed in zymosan-treated 
mice, in agreement with prior studies. We also observed long-lasting reductions in ambulatory, vertical, stereotypic and jump counts, as well as travel distance, in zymosantreated mice when tested in the open field. These findings suggest that the abdominal visceral pain caused by zymosan influences the spontaneous responses and action intention of mice. A similar phenomenon of reduced activity occurs in people suffering from IBS, as well $[59,60]$. Thus, spontaneous visceral pain induced by intracolonic injection of zymosan could be measured via decreased spontaneous activity in the open field. Moreover, measurement of spontaneous activities in the open field test could be used to predict the ability of experimental IBS therapies to reduce spontaneous visceral pain.

\section{Zymosan-treated mice exhibited persistent anxiety-like behaviors}

There is a high rate of co-morbidity between IBS and psychological disorders such as anxiety, stress and depression [11-15]. We demonstrated that zymosan-treated mice experienced more anxiety compared to saline-treated mice, as measured by the distance traveled and time spent in the central zone in the open field test and using the elevated plus maze and the light/dark box tests. Thus, visceral noxious stimulation is interpreted to cause interoceptive anxiety in zymosan-treated mice. Previous human and animal studies also showed that anxiety-like behaviors could be induced by inflammatory pain, chronic musculoskeletal pain or neuropathic pain [61-67]; but see [68]. In addition, recent research suggests that dysbiosis of the gut microbiota is implicated in the pathogenesis of IBS [69]. Commensal bacteria are known to affect a variety of complex behaviors, including social, emotional, and anxiety-like behaviors, and contribute to brain development and function in mice and human [70,71]. Thus, intracolonic treatment with zymosan may cause intestinal dysbiosis and lead to anxiety.

\section{Effects of NB001 on zymosan-treated mice}

$\mathrm{AC} 1$ is activated by calcium-calmodulin- (CaM-) dependent manner. It acts downstream from glutamate NMDA receptors and contributes to chronic pain-related neuronal plasticity in the cortex and spinal cord $[18,19,33,34,53,54]$. In the present study, NB001, an AC1 inhibitor, exerted obvious antinociceptive effects on visceral pain induced by intracolonic injection of zymosan. Because NB001 has no effect on motor function in normal mice [37], we speculate that NB001 increases the spontaneous behaviors of zymosan-treated mice by attenuating spontaneous visceral pain. Our data suggest that the AC1 signaling pathway plays an important role in the processing of visceral pain induced by intracolonic injection of zymosan. According to the MPI, the ambulatory counts may be the most sensitive parameter to predict the analgesic effects of drugs on spontaneous visceral pain.

NB001 did not dampen anxiety-like behaviors in zymosan-treated mice, consistent with our previous finding that NB001 had no effect on anxiety-like behaviors in normal mice [37]. We believe that pain causes cortical plasticity and that brains likely exhibit 'metaplasticity' in response to continuous inputs from the periphery $[18,72]$. Thus, persistent, noxious visceral stimuli in the present study were able to cause a long-lasting pain-related emotional disorder, in this case anxiety. In addition, although pain-related anxiety is coupled to pain, growing evidence indicates that pain-related anxiety is dissociated from pain perception [73]; this finding provides an explanation for our observations that NB001 is unable to alleviate zymosan-induced anxiety by attenuating visceral pain in mice and that gabapentin can reduce anxious behaviors by a mechanism unrelated to antinociception. More research is needed to find additional methods for attenuating paininduced anxiety.

\section{Effects of gabapentin on zymosan-treated mice}

Gabapentin interacts with a subunit of voltage-sensitive calcium $\left(\mathrm{Ca}^{2+}\right)$ channels [74] and modulates the function of peripheral and central pain pathways by influencing fast synaptic transmission and neuronal excitability $[75,76]$. Consistent with previous work, our data suggest that gabapentin relieves chronic visceral pain induced by intracolonic injection of zymosan and reduces spontaneous pain through a multiplicity of mechanisms. In addition, gabapentin has also been associated with a reversal of anxiety-like behaviors in animal models of neuropathic pain $[77,78]$. The present results indicated that gabapentin significantly decreases anxiety-like behaviors in zymosan-treated mice, which is coincident with its anti-nociceptive effect. Our observation that gabapentin reduces anxiety-like behaviors in zymosantreated mice provides evidence to support the potential use of gabapentin for the treatment of IBS-related emotional disorders. However, the side effects of gabapentin, including hepatotoxicity and neurologic toxicities [79-81], should be taken into account if this drug is considered for the symptomatic treatment of IBS.

For the first time, we have presented evidence that changes in spontaneous behavioral responses are a reflection of spontaneous pain induced by intracolonic injection of zymosan. Mice with zymosan-induced colitis exhibited significant increases in anxiety-like behaviors. We first demonstrated that the expression of Fos protein is notably increased in several brain areas, and particularly in regions involved in the processing of pain and emotions; this finding suggests that these cortical and subcortical areas are involved in the response to zymosan-induced colitis. From the point of view of translational medicine, 
we found that IP injection of NB001 relieved spontaneous visceral pain induced by intracolonic injection of zymosan but had no effect on anxiety, whereas IP injection of gabapentin alleviated both spontaneous visceral pain and anxiety in zymosan-treated mice. Our findings provide a basis for these drugs to be considered for the clinical pharmacological treatment of IBS.

\section{Methods}

\section{Animals}

Experiments were performed with adult (age 8-12 weeks) male C57/BL6 mice purchased from Charles River Laboratories (St. Constant, Quebec, Canada). Animals were housed under standard laboratory conditions (12 h light/ $12 \mathrm{~h}$ dark, temperature $22-26^{\circ} \mathrm{C}$, humidity $55-60 \%$ ) with water and mice chow available ad libitum. All experiments were performed in accordance with protocols approved by the Animal Care Committee of the University of Toronto and Animal Care and Use Committee of the Fourth Military Medical University.

\section{Zymosan-induced colitis in animals}

Colitis was induced in animals by the administration of zymosan, as described previously $[41,47,48]$. Mice were anesthetized by isoflurane inhalation (1-3\%, or as needed). During surgery, body temperature was maintained at $37^{\circ} \mathrm{C}$ using a heating pad. A lubricant ointment (artificial tears) was applied to the eyes. A volume of $0.1 \mathrm{ml}$ zymosan suspension (30 $\mathrm{mg} / \mathrm{ml}$ in saline; derived from Saccharomyces cerevisiae; Sigma, St. Louis, MO) was administered transanally via a 22-gauge, 24-mm-long stainless-steel feeding needle into the colons of mice over a period of $2 \mathrm{~min}$. A control group of mice was subjected to a similar procedure except that $0.1 \mathrm{ml}$ saline was administered transanally. Zymosan or saline were given daily for three consecutive days.

\section{Immunohistochemical staining}

On day 7, zymosan-treated mice and saline-treated mice were deeply anesthetized and perfused with $50 \mathrm{ml}$ of $0.9 \%$ saline, followed by $100 \mathrm{ml}$ of $0.1 \mathrm{M} \mathrm{PB}$ containing $4 \%(\mathrm{w} / \mathrm{v})$ paraformaldehyde. Immediately after perfusion, brains were removed and placed into $0.1 \mathrm{M} \mathrm{PB}$ containing $30 \%(\mathrm{w} / \mathrm{v})$ sucrose overnight at $4{ }^{\circ} \mathrm{C}$ and cut into $25 \mu \mathrm{m}$ thick serial frontal sections on a freezing microtome (Kryostat 1720; Leitz, Mannheim, Germany). The sections were collected in sequence, divided into 2 series and washed with $0.01 \mathrm{M}$ phosphate buffer solution (PBS, $\mathrm{pH}$ 7.4). The sections were incubated with mouse anti-Fos antiserum (1:500; Abcam, Cambridge, MA, USA) in PBS containing $5 \%(\mathrm{v} / \mathrm{v})$ normal donkey serum (NDS), 0.3\% (v/v) Triton X-100, 0.05\% (w/v) $\mathrm{NaN}_{3}$ and $0.25 \%(\mathrm{w} / \mathrm{v})$ carrageenan (PBS-NDS, $\mathrm{pH} 7.4$ ) overnight at $4^{\circ} \mathrm{C}$.
Next, the sections were washed and then incubated with biotinylated anti-mouse IgG (1:200, Millipore Corporation, USA) for $2 \mathrm{~h}$ at room temperature (approximately $\left.22^{\circ} \mathrm{C}\right)$. Sections were then washed $(3 \times 10 \mathrm{~min})$ in PBS and incubated in avidin-biotin complex (ABC kit, Vector Laboratories, Inc., USA) for $30 \mathrm{~min}$. After incubation in avidin-biotin complex, sections were washed $(3 \times 10 \mathrm{~min})$ again and reacted with $0.05 \mathrm{M}$ of Tris- $\mathrm{HCl}$ buffer (pH 7.6) containing $0.04 \%$ diaminobenzidinetetrahydrochloride (DAB) (Dojin, Kumamoto, Japan) and $0.003 \% \mathrm{H}_{2} \mathrm{O}_{2}$ for visualizing Fos; Fos-positive nuclei appear dark brown. Sections were washed again (once immediately after removing the $\mathrm{DAB}$ solution, then $3 \times 10 \mathrm{~min}$ ), then mounted on gelatin-coated glass slides, and allowed to air dry overnight. Sections were dehydrated in increasing concentrations of ethanol, cleared, and coverslipped for examination by light microscopy (AHBT3; Olympus, Tokyo, Japan).

\section{Quantification of Fos expression}

The counts of Fos-ir neurons in the brain regions were represented as the average number of neurons per section. We limited our analysis to the PFC, ACC, insular cortex, amygdala, PAG, NTS, and PBN because most immunolabeled neurons in the brains of zymosan-treated mice were in these regions. The numbers of labeled neurons in a given brain region were estimated from the counts of positively stained cells in a minimum of 6 sections per brain region. To avoid counting a neuron more than once, sections used for the counts were separated by at least $100 \mu \mathrm{m}$. The differences in cell counts were evaluated statistically by unpaired $t$-test to examine the interactions among groups. Counting was performed by an investigator who was blind to the treatment condition.

\section{Behavioral testing}

Counts of visceral pain behaviors: Visceral pain behaviors, as described by Laird [49], included licking of the abdomen in the absence of other grooming behavior, wholebody stretching, flattening the abdomen against the floor, or contracting the abdominal wall such that an arched posture was adopted for 1-2 sec (abdominal retractions). The total number of visceral pain behaviors was recorded over a period of $10 \mathrm{~min}$.

Open field: Mice were placed in a novel open field $\left(43.2 \times 43.2 \times 30.5 \mathrm{~cm}^{3}\right.$; Med Associates, St. Albans, Vermont) inside a dimly lit isolation chamber ( $<50$ lux in the center of the open field) with a fan. An activity monitoring system (Activity Monitor, Med Associates, St. Albans, Vermont) was used to record horizontal locomotor activity. Briefly, this system uses paired sets of photo beams to detect movement (number of photo beams: 16; space between the beams: $2.5 \mathrm{~cm}$; number 
of zones: X: 17, Y: 17). Each animal was placed in the center of the open field, and activity was measured for $30 \mathrm{~min}$. Central zone was defined by zones from $(4,4)$ to $(13,13)$.

Elevated plus maze: The elevated plus maze (Med Associates, St. Albans, Vermont) consisted of two open arms in line with each other placed perpendicularly to two closed arms in line with each other [82]. The maze was situated $70 \mathrm{~cm}$ from the floor. For each test, individual animals were placed in the center square with the head facing a closed arm. The number of entries into and time spent in each arm were recorded for $5 \mathrm{~min}$.

Light/dark box: The light/dark box used in this study was a modified version of a light/dark box described previously by Kim et al. [23]. The apparatus consisted of a rectangular Plexiglas box $\left(44 \times 8.5 \times 25 \mathrm{~cm}^{3}\right)$ divided into equal-size light and dark compartments separated by a door. The light box was lit by a $60-\mathrm{W}$ desk lamp (400 lux) placed $30 \mathrm{~cm}$ above the box. Each animal was placed in the dark compartment and was allowed 20 section to explore, after which the door to the light compartment was opened. The time until the animal left the dark box and the time spent in the light box were recorded for $10 \mathrm{~min}$.

Mice were acclimatized to the observation room for $30 \mathrm{~min}$ prior to behavioral tests. The behavioral tests were performed by an investigator who was blind to the treatment condition from 9:00 am to 12:00 pm.

\section{Drugs injection}

Mice were administered NB001 $3 \mathrm{mg} / \mathrm{kg}$ or gabapentin (Tocris Bioscience) $30 \mathrm{mg} / \mathrm{kg}$ IP prior to behavioral tests.

\section{Statistical analysis}

All data were collected by experimenters who were blind to the surgical and chemical treatments. Statistical analysis was performed using SPSS software (version 21). Data were expressed as the mean \pm standard error of the mean (mean \pm S.E.M.). Inhibition of visceral pain or anxiety was presented as maximum possible inhibition $(\mathrm{MPI})=\left(\mathrm{P}_{\text {drug }}-\mathrm{P}_{\text {zymosan }}\right) /\left(\mathrm{P}_{\text {saline }}-\mathrm{P}_{\text {zymosan }}\right) \times 100 \%$ $\left(\mathrm{P}_{\text {drug: }}\right.$ value of parameter detected in each behavior test in zymosan-treated mice with NB001 or gabapentin IP injection; $\mathrm{P}_{\text {zymosan }}$ : value of parameter detected in each behavior test in mice with zymosan intracolonic treatment;

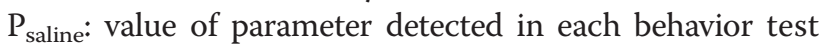
in mice with saline intracolonic treatment). When necessary, statistical significance was assessed by unpaired $t$-test, repeated measures ANOVA followed by post hoc comparison with LSD test, one way ANOVA, two-way ANOVA followed by post hoc comparison with LSD test or two-way ANOVA followed by post hoc comparison with Dunnett's test. A threshold for statistical significance of $P<0.05$ was chosen.

\section{Abbreviations}

AC: Adenylyl cyclase; ACC: Anterior cingulate cortex; ACSF: Artificial cerebrospinal fluid; Amy: Amygdala; cc: Central canal; CeA: Central amygdala; DAB: Diaminobenzidinetetrahydrochloride; IBS: Irritable bowel syndrome; IC: insular cortex; MPI: Maximum possible inhibition; PAG: Periaqueductal gray; PBN: Parabrachial nucleus; PBS: Phosphate buffer solution;

PFC: Prefrontal cortex; NTS: Nucleus of solitary tract.

\section{Competing interests}

The authors declare that they have no competing interests.

\section{Authors' contributions}

$M M Z$ and $S B L$ are responsible for performance of experiments and writing the manuscript. TZ and KK are responsible for collecting data. MMZ and MZ are responsible for experimental design and writing the manuscript. All authors read and approved the final manuscript.

\section{Acknowledgements}

This work was supported by Canada Research Chair, Canadian Institute for Health Research (258523), NSERC (Natural Sciences and Engineering Research Council of Canada) discovery grant (RGPIN 402555), and The Azrieli Foundation and Brain Canada (MZ), and National Natural Science Foundation of China (Nos. 31010103909, 81371239) (YQL). MMZ is supported by China Scholarship Council. KK is supported by the postdoctoral fellowship from Fragile $X$ research foundation of Canada. The authors would like to thank $\mathrm{Ng}$ Pamela for proof reading.

\section{Author details}

${ }^{1}$ Department of Anatomy, Histology, Embryology \& K. K. Leung Brain Research Centre, The Fourth Military Medical University, Xian, Shanxi 710032, China. ${ }^{2}$ Department of Physiology, Faculty of Medicine, University of Toronto, 1 King's College Circle, Toronto, Ontario M5S 1A8, Canada. ${ }^{3}$ Center for Neuron and Disease, Frontier Institutes of Life Science, and Science and Technology, Xi'an Jiaotong University, 28 Xianning West Road, Xian, Shanxi 710049, China.

Received: 23 May 2014 Accepted: 10 June 2014

Published: 16 June 2014

\section{References}

1. Mayer EA, Raybould HE: Role of visceral afferent mechanisms in functional bowel disorders. Gastroenterology 1990, 99:1688-1704.

2. Cervero F, Laird JM: Visceral pain. Lancet 1999, 353:2145-2148.

3. Blackshaw LA, Gebhart GF: The pharmacology of gastrointestinal nociceptive pathways. Curr Opin Pharmacol 2002, 2:642-649.

4. Ness TJ, Gebhart GF: Visceral pain: a review of experimental studies. Pain 1990, 41:167-234.

5. Barbara G, Cremon C, De Giorgio R, Dothel G, Zecchi L, Bellacosa L, Carini G, Stanghellini V, Corinaldesi R: Mechanisms underlying visceral hypersensitivity in irritable bowel syndrome. Curr Gastroenterol Rep 2011, 13:308-315.

6. Feng B, Kiyatkin ME, La JH, Ge P, Solinga R, Silos-Santiago I, Gebhart GF: Activation of guanylate cyclase- $C$ attenuates stretch responses and sensitization of mouse colorectal afferents. J Neurosci 2013, 33:9831-9839.

7. Feng B, La JH, Schwartz ES, Gebhart GF: Irritable bowel syndrome: methods, mechanisms, and pathophysiology. Neural and neuro-immune mechanisms of visceral hypersensitivity in irritable bowel syndrome. Am J Physiol Gastrointest Liver Physiol 2012, 302:G1085-G1098.

8. Christianson JA, Bielefeldt K, Altier C, Cenac N, Davis BM, Gebhart GF, High KW, Kollarik M, Randich A, Undem B, Vergnolle N: Development, plasticity and modulation of visceral afferents. Brain Res Rev 2009, 60:171-186.

9. Cervero F, Laird JM: Understanding the signaling and transmission of visceral nociceptive events. J Neurobiol 2004, 61:45-54.

10. Fond G, Loundou A, Hamdani N, Boukouaci W, Dargel A, Oliveira J, Roger M, Tamouza R, Leboyer M, Boyer L: Anxiety and depression comorbidities in irritable bowel syndrome (IBS): a systematic review and meta-analysis. Eur Arch Psychiatry Clin Neurosci 2014. Epub ahead of print.

11. Canavan C, West J, Card T: The epidemiology of irritable bowel syndrome. Clin Epidemiol 2014, 6:71-80.

12. Farmer $A D, A z i z Q$ : Visceral pain hypersensitivity in functional gastrointestinal disorders. Br Med Bull 2009, 91:123-136. 
13. Mikocka-Walus AA, Turnbull DA, Andrews JM, Moulding NT, Wilson IG, Harley HA, Hetzel DJ, Holtmann GJ: Psychological problems in gastroenterology outpatients: A South Australian experience. Psychological co-morbidity in IBD, IBS and hepatitis C. Clin Pract Epidemiol Ment Health 2008, 4:15.

14. Dinan TG, Quigley EM, Ahmed SM, Scully P, O'Brien S, O'Mahony L, O'Mahony S, Shanahan F, Keeling PW: Hypothalamic-pituitary-gut axis dysregulation in irritable bowel syndrome: plasma cytokines as a potential biomarker? Gastroenterology 2006, 130:304-311.

15. Fukudo S: Stress and visceral pain: focusing on irritable bowel syndrome. Pain 2013, 154(Suppl 1):S63-S70.

16. Zhao MG, Toyoda H, Lee YS, Wu LJ, Ko SW, Zhang XH, Jia Y, Shum F, Xu H, Li BM, Kaang BK, Zhuo M: Roles of NMDA NR2B subtype receptor in prefrontal long-term potentiation and contextual fear memory. Neuron 2005, 47:859-872.

17. Descalzi G, Li XY, Chen T, Mercaldo V, Koga K, Zhuo M: Rapid synaptic potentiation within the anterior cingulate cortex mediates trace fear learning. Mol Brain 2012, 5:6.

18. Zhuo M: Cortical excitation and chronic pain. Trends Neurosci 2008 31:199-207.

19. Qiu S, Chen T, Koga K, Guo YY, Xu H, Song Q, Wang JJ, Descalzi G, Kaang BK, Luo JH, Zhuo M, Zhao MG: An increase in synaptic NMDA receptors in the insular cortex contributes to neuropathic pain. Sci Signal 2013, 6:ra34.

20. Wei F, Wang GD, Kerchner GA, Kim SJ, Xu HM, Chen ZF, Zhuo M: Genetic enhancement of inflammatory pain by forebrain NR2B overexpression. Nat Neurosci 2001, 4:164-169.

21. Vogt BA: Pain and emotion interactions in subregions of the cingulate gyrus. Nat Rev Neurosci 2005, 6:533-544.

22. Zhuo M: Long-term potentiation in the anterior cingulate cortex and chronic pain. Philos Trans R Soc Lond B Biol Sci 2014, 369:20130146.

23. Kim SS, Wang H, Li XY, Chen T, Mercaldo V, Descalzi G, Wu LJ, Zhuo M: Neurabin in the anterior cingulate cortex regulates anxiety-like behavior in adult mice. Mol Brain 2011, 4:6.

24. Larsson MB, Tillisch K, Craig AD, Engstrom M, Labus J, Naliboff B, Lundberg $P$, Strom M, Mayer EA, Walter SA: Brain responses to visceral stimuli reflect visceral sensitivity thresholds in patients with irritable bowel syndrome. Gastroenterology 2012, 142:463-472. e463.

25. Morgan V, Pickens D, Gautam S, Kessler R, Mertz H: Amitriptyline reduces rectal pain related activation of the anterior cingulate cortex in patients with irritable bowel syndrome. Gut 2005, 54:601-607.

26. Kwan CL, Diamant NE, Pope G, Mikula K, Mikulis DJ, Davis KD: Abnormal forebrain activity in functional bowel disorder patients with chronic pain. Neurology 2005, 65:1268-1277.

27. Lee HF, Hsieh JC, Lu CL, Yeh TC, Tu CH, Cheng CM, Niddam DM, Lin HC, Lee FY, Chang FY: Enhanced affect/cognition-related brain responses during visceral placebo analgesia in irritable bowel syndrome patients. Pain 2012, 153:1301-1310.

28. Elsenbruch S, Rosenberger C, Enck P, Forsting M, Schedlowski M, Gizewski ER: Affective disturbances modulate the neural processing of visceral pain stimuli in irritable bowel syndrome: an fMRI study. Gut 2010, 59:489-495.

29. Gibney SM, Gosselin RD, Dinan TG, Cryan JF: Colorectal distension-induced prefrontal cortex activation in the Wistar-Kyoto rat: implications for irritable bowel syndrome. Neuroscience 2010, 165:675-683.

30. Verne GN, Himes NC, Robinson ME, Gopinath KS, Briggs RW, Crosson B, Price DD: Central representation of visceral and cutaneous hypersensitivity in the irritable bowel syndrome. Pain 2003, 103:99-110.

31. Zhuo M: A synaptic model for pain: long-term potentiation in the anterior cingulate cortex. Molecules and cells 2007, 23:259-271.

32. Wei F, Li P, Zhuo M: Loss of synaptic depression in mammalian anterior cingulate cortex after amputation. J Neurosci 1999, 19:9346-9354.

33. Zhuo M: Targeting neuronal adenylyl cyclase for the treatment of chronic pain. Drug Discov Today 2012, 17:573-582.

34. Xu H, Wu LJ, Wang H, Zhang X, Vadakkan Kl, Kim SS, Steenland HW, Zhuo $M$ : Presynaptic and postsynaptic amplifications of neuropathic pain in the anterior cingulate cortex. J Neurosci 2008, 28:7445-7453.

35. Liauw J, Wu LJ, Zhuo M: Calcium-stimulated adenylyl cyclases required for long-term potentiation in the anterior cingulate cortex. J Neurophysiol 2005, 94:878-882.

36. Li XY, Ko HG, Chen T, Descalzi G, Koga K, Wang H, Kim SS, Shang Y, Kwak C, Park SW, Shim J, Lee K, Collingridge GL, Kaang BK, Zhuo M: Alleviating neuropathic pain hypersensitivity by inhibiting PKMzeta in the anterior cingulate cortex. Science 2010, 330:1400-1404.
37. Wang H, Xu H, Wu LJ, Kim SS, Chen T, Koga K, Descalzi G, Gong B, Vadakkan Kl, Zhang X, Kaang BK, Zhuo M: Identification of an adenylyl cyclase inhibitor for treating neuropathic and inflammatory pain. Sci Trans/ Med 2011, 3:65ra63.

38. Wei F, Qiu CS, Kim SJ, Muglia L, Maas JW, Pineda W, Xu HM, Chen ZF, Storm DR, Muglia LJ, Zhuo M: Genetic elimination of behavioral sensitization in mice lacking calmodulin-stimulated adenylyl cyclases. Neuron 2002, 36:713-726.

39. Vadakkan KI, Wang H, Ko SW, Zastepa E, Petrovic MJ, Sluka KA, Zhuo M: Genetic reduction of chronic muscle pain in mice lacking calcium/ calmodulin-stimulated adenylyl cyclases. Mol Pain 2006, 2:7.

40. Coutinho SV, Meller ST, Gebhart GF: Intracolonic zymosan produces visceral hyperalgesia in the rat that is mediated by spinal NMDA and non-NMDA receptors. Brain Res 1996, 736:7-15.

41. Jones RC 3rd, Otsuka E, Wagstrom E, Jensen CS, Price MP, Gebhart GF: Short-term sensitization of colon mechanoreceptors is associated with long-term hypersensitivity to colon distention in the mouse. Gastroenterology 2007, 133:184-194.

42. Acharya NV, Pickering RM, Wilton LW, Shakir SA: The safety and effectiveness of newer antiepileptics: a comparative postmarketing cohort study. J Clin Pharmacol 2005, 45:385-393.

43. Kang MG, Felix R, Campbell KP: Long-term regulation of voltage-gated Ca (2+) channels by gabapentin. FEBS Lett 2002, 528:177-182.

44. Attal N, Cruccu G, Baron R, Haanpaa M, Hansson P, Jensen TS, Nurmikko T: EFNS guidelines on the pharmacological treatment of neuropathic pain: 2010 revision. Eur J Neurol 2010, 17:1113-e1188.

45. Coggeshall RE: Fos, nociception and the dorsal horn. Prog Neurobiol 2005, 77:299-352

46. Zhang MM, Ji W, Pei LY, Wang W, Chen T, Li H, Zhang T, Wu SX, Li YQ: Acute colitis induces neurokinin 1 receptor internalization in the rat lumbosacral spinal cord. PLoS One 2013, 8:e59234.

47. Shinoda M, Feng B, Gebhart GF: Peripheral and central P2X receptor contributions to colon mechanosensitivity and hypersensitivity in the mouse. Gastroenterology 2009, 137:2096-2104.

48. Shinoda M, La JH, Bielefeldt K, Gebhart GF: Altered purinergic signaling in colorectal dorsal root ganglion neurons contributes to colorectal hypersensitivity. J Neurophysiol 2010, 104:3113-3123.

49. Laird JM, Martinez-Caro L, Garcia-Nicas E, Cervero F: A new model of visceral pain and referred hyperalgesia in the mouse. Pain 2001 92:335-342.

50. Prut $L$, Belzung $C$ : The open field as a paradigm to measure the effects of drugs on anxiety-like behaviors: a review. Eur J Pharmacol 2003, 463:3-33.

51. Carola V, D'Olimpio F, Brunamonti E, Mangia F, Renzi P: Evaluation of the elevated plus-maze and open-field tests for the assessment of anxiety-related behaviour in inbred mice. Behav Brain Res 2002, 134:49-57.

52. Bourin M, Hascoet M: The mouse light/dark box test. Eur J Pharmacol 2003, 463:55-65.

53. Wang H, Gong B, Vadakkan Kl, Toyoda H, Kaang BK, Zhuo M: Genetic evidence for adenylyl cyclase 1 as a target for preventing neuronal excitotoxicity mediated by $\mathrm{N}$-methyl-D-aspartate receptors. J Biol Chem 2007, 282:1507-1517.

54. Zhuo M: Neuronal mechanism for neuropathic pain. Mol Pain 2007, 3:14.

55. Shamsi Meymandi M, Keyhanfar F: Relative potency of pregabalin, gabapentin, and morphine in a mouse model of visceral pain. Can J Anaesth 2013, 60:44-49.

56. O' Mahony SM, Coelho AM, Fitzgerald P, Lee K, Winchester W, Dinan TG, Cryan JF: The effects of gabapentin in two animal models of co-morbid anxiety and visceral hypersensitivity. Eur J Pharmacol 2011, 667:169-174.

57. Yamamoto T, Takemura M, Inui T, Torii K, Maeda N, Ohmoto M, Matsumoto I, Abe K: Functional organization of the rodent parabrachial nucleus. Ann N Y Acad Sci 2009, 1170:378-382.

58. Hermes SM, Colbert JF, Aicher SA: Differential content of vesicular glutamate transporters in subsets of vagal afferents projecting to the nucleus tractus solitarii in the rat. J Comp Neurol 2014, 522:642-653.

59. Hungin AP, Chang L, Locke GR, Dennis EH, Barghout V: Irritable bowel syndrome in the United States: prevalence, symptom patterns and impact. Aliment Pharmacol Ther 2005, 21:1365-1375.

60. Hungin AP, Whorwell PJ, Tack J, Mearin F: The prevalence, patterns and impact of irritable bowel syndrome: an international survey of 40,000 subjects. Aliment Pharmacol Ther 2003, 17:643-650. 
61. Li Q, Yue N, Liu SB, Wang ZF, Mi WL, Jiang JW, Wu GC, Yu J, Wang YQ: Effects of chronic electroacupuncture on depression- and anxiety-like behaviors in rats with chronic neuropathic pain. Evid Based Complement Alternat Med 2014, 2014:158987.

62. Zhang S, Jin X, You Z, Wang S, Lim G, Yang J, McCabe M, Li N, Marota J, Chen $L$, Mao J: Persistent nociception induces anxiety-like behavior in rodents: Role of endogenous neuropeptide S. Pain 2014. Epub ahead of print.

63. Do Nascimento GC, Leite-Panissi CR: Time-dependent analysis of nociception and anxiety-like behavior in rats submitted to persistent inflammation of the temporomandibular joint. Physiol Behav 2014, 125:1-7.

64. Bushnell MC, Ceko M, Low LA: Cognitive and emotional control of pain and its disruption in chronic pain. Nat Rev Neurosci 2013, 14:502-511.

65. Bair MJ, Wu J, Damush TM, Sutherland JM, Kroenke K: Association of depression and anxiety alone and in combination with chronic musculoskeletal pain in primary care patients. Psychosom Med 2008, 70:890-897.

66. Dimova V, Horn C, Parthum A, Kunz M, Schofer D, Carbon R, Griessinger N, Sittl R, Lautenbacher $S$ : Does severe acute pain provoke lasting changes in attentional and emotional mechanisms of pain-related processing? A longitudinal study. Pain 2013, 154:2737-2744.

67. Grupe DW, Nitschke JB: Uncertainty and anticipation in anxiety: an integrated neurobiological and psychological perspective. Nat Rev Neurosci 2013, 14:488-501.

68. Urban R, Scherrer G, Goulding EH, Tecott LH, Basbaum Al: Behavioral indices of ongoing pain are largely unchanged in male mice with tissue or nerve injury-induced mechanical hypersensitivity. Pain 2011, 152:990-1000.

69. Blumberg R, Powrie F: Microbiota, disease, and back to health: a metastable journey. Sci Transl Med 2012, 4:137rv137.

70. Collins SM, Bercik P: Gut microbiota: Intestinal bacteria influence brain activity in healthy humans. Nat Rev Gastroenterol Hepatol 2013, 10:326-327.

71. Collins SM, Surette M, Bercik P: The interplay between the intestinal microbiota and the brain. Nat Rev Microbiol 2012, 10:735-742.

72. Zhuo M: Cortical plasticity as a new endpoint measurement for chronic pain. Mol Pain 2011, 7:54.

73. Grachev ID, Fredickson BE, Apkarian AV: Dissociating anxiety from pain: mapping the neuronal marker $\mathrm{N}$-acetyl aspartate to perception distinguishes closely interrelated characteristics of chronic pain. $\mathrm{Mol}$ Psychiatry 2001, 6:256-258.

74. Taylor CP: Mechanisms of action of gabapentin. Rev Neurol (Paris) 1997, 153(Suppl 1):S39-S45.

75. Giordanetto F, Knerr L, Wallberg A: T-type calcium channels inhibitors: a patent review. Expert Opin Ther Pat 2011, 21:85-101.

76. Klimis H, Adams DJ, Callaghan B, Nevin S, Alewood PF, Vaughan CW, Mozar CA, Christie MJ: A novel mechanism of inhibition of high-voltage activated calcium channels by alpha-conotoxins contributes to relief of nerve injury-induced neuropathic pain. Pain 2011, 152:259-266.

77. Roeska K, Doods H, Arndt K, Treede RD, Ceci A: Anxiety-like behaviour in rats with mononeuropathy is reduced by the analgesic drugs morphine and gabapentin. Pain 2008, 139:349-357.

78. Wallace VC, Segerdahl AR, Blackbeard J, Pheby T, Rice AS: Anxiety-like behaviour is attenuated by gabapentin, morphine and diazepam in a rodent model of HIV anti-retroviral-associated neuropathic pain. Neurosci Lett 2008, 448:153-156.

79. Bookwalter T, Gitlin M: Gabapentin-induced neurologic toxicities. Pharmacotherapy 2005, 25:1817-1819.

80. Lasso-de-la-Vega MC, Zapater P, Such J, Perez-Mateo M, Horga JF: Gabapentin-associated hepatotoxicity. Am J Gastroenterol 2001, 96:3460-3462.

81. Dogukan A, Aygen B, Berilgen MS, Dag S, Bektas S, Gunal Al: Gabapentin-induced coma in a patient with renal failure. Hemodial Int 2006, 10:168-169.

82. Hogg S: A review of the validity and variability of the elevated plus-maze as an animal model of anxiety. Pharmacol Biochem Behav 1996, 54:21-30.

doi:10.1186/1756-6606-7-47

Cite this article as: Zhang et al:: Effects of NB001 and gabapentin on irritable bowel syndrome-induced behavioral anxiety and spontaneous pain. Molecular Brain 2014 7:47.

\section{Submit your next manuscript to BioMed Central and take full advantage of:}

- Convenient online submission

- Thorough peer review

- No space constraints or color figure charges

- Immediate publication on acceptance

- Inclusion in PubMed, CAS, Scopus and Google Scholar

- Research which is freely available for redistribution

Submit your manuscript at www.biomedcentral.com/submit 